Note

\section{Stopped-Flow Circular Dichroism Study on Conformational Change of Alpha-Chymotrypsin by Sodium Dodecyl Sulfate}

\author{
Kunio TAKEDA and Shigeaki TAKAGI* \\ Department of Applied Chemistry, Faculty of Science, \\ Okayama University of Science, \\ Ridai, Okayama 700, Japan \\ * Department of Agricultural Chemistry, \\ Faculty of Agriculture, \\ Okayama University, \\ Tsushima-naka, Okayama 700, Japan
}

Received September 11, 1980

Conformations of Protein in aqueous solution can be more intrinsically detected by circular dichroism (CD) measurements. Recently, a few stopped-flow CD studies have been made in visible and near ultraviolet regions. ${ }^{1}$ 5) In the case of detection of the conformational change of protein, however, the kinetic measurements should be done around $200 \mathrm{~nm}$ in far ultraviolet region, the ellipticity at which most reflects the change in protein backbone structure. On the other hand, it has been found that $\alpha$ chymotrypsin adopts a conformation of a higher helix content than the native protein by the addition of sodium dodecyl sulfate (SDS). ${ }^{6}$ Now, the authors wish to report the application of stopped-flow CD spectroscopy in far ultraviolet region to conformational change of the protein.

Crystalline $\alpha$-chymotrypsin from beef pancreas was purchased from Miles Laboratories. The concentration of the protein was determined spectrophotometrically using $E_{1 \mathrm{~cm}}^{1 \%}=20.6$ at $282 \mathrm{~nm}$. The surfactant, SDS was purchased from BDH Chemicals Ltd. and the critical micelle concentration (CMC) of it in pure water was determined to be $8.3 \times 10^{-3} \mathrm{~mol} / \mathrm{liter}$ at $25^{\circ} \mathrm{C}$ by the electrical conductivity method. The $\alpha$-chymotrypsin-SDS interaction was studied in a buffer solution of $\mathrm{pH} \mathrm{7.0,} \mathrm{containing}$ $3.33 \times 10^{-3}$ and $3.56 \times 10^{-3} \mathrm{~mol} / \mathrm{liter}$ of $\mathrm{Na}_{2} \mathrm{HPO}_{4}$ and $\mathrm{NaH}_{2} \mathrm{PO}_{4}$, respectively. ${ }^{*}$

* The rather dilute buffer was used because the higher the salt concentration, the lower the SDS concentration at which the final conformational change of protein is attained and thus detailed studies on the conformational change become difficult. This change in the buffer concentration shows no significant effects on the mode of circular dichroic spectra and the binding isotherm (not shown). The CMC of SDS in the buffer was $5.6 \times 10^{-3}$ mol/liter at $25^{\circ} \mathrm{C}$ by the electrical conductivity method.
The measurements of $\mathrm{CD}$ were carred out with a JASCO J-500A spectropolarimeter of Japan Spectroscopic Co., equipped with a DP-501 data processor of the same company. The data processor has been partially modified to follow rapid reactions. The time constant and the scanning speed of the apparatus are variable from $2.5 \times 10^{-4}$ to $0.64 \mathrm{sec}$ and from 1.0 to $1000 \mathrm{~nm} / \mathrm{min}$, respectively. The sampling time required for 5 data points/nm on chart for both $\mathrm{X}$ and $\mathrm{Y}$ directions can be selected from $1.0 \times 10^{-4}$ to $0.10 \mathrm{sec}$ for kinetic measurements. The stopped-flow measurements by CD detection were made with a rapid mixer, model MX-70 of Union Giken Co, and a handmade observation cell. The passlength and the incident area of the cell were $1 \mathrm{~mm}$ and $1 \mathrm{~cm}^{2}$, respectively. The system of stopped-fiow was derived at about $2.0 \mathrm{~kg} / \mathrm{cm}^{2}$ pressure of gas. Under these conditions, the dead volume beyond the mixer and the dead time were calculated to be $250 \mu \mathrm{l}$ and $2 \mathrm{sec}$, respectively.

The CD spectra were measured within $5 \mathrm{~min}$ after mixing the solution of the protein with those of SDS.** Figure 1 shows the representative $C D$ spectra in the absence and the presence of $2.0 \times 10^{-2} \mathrm{~mol} / \mathrm{iter} \mathrm{SDS}$. Although the observed spectrum does not show a double negative maximum at 206 and $222 \mathrm{~nm}$ characterizing $\alpha$ helical structure, the content of such a structure increases as mentioned by Hunt and Jirgensons. ${ }^{6}$ In the CD stopped-flow measurements, ellipticity changes were observed with time above $5.0 \times 10^{-3} \mathrm{~mol} / \mathrm{liter}$ of SDS (the concentration of the protein was $1.0 \times 10^{-5} \mathrm{~mol} / \mathrm{liter}$ ). The rate was dependent on the SDS concentration up to $2.0 \times 10^{-2} \mathrm{~mol} / \mathrm{liter}$. The representative time courses at 195 (at which the positive maximum appears in the difference CD spectrum in Fig. 1), 206 and $222 \mathrm{~nm}$ are shown in Fig. 2 (a-c). Half of the total ellipticity change were observed with time at each wavelength in comparing with the spectra in Fig. 1. However, as anticipated from the results in Fig. 1, the ellipticity at $195 \mathrm{~nm}$ and those at 206 and $222 \mathrm{~nm}$ changed upward and downward with time, respectively, in Fig. 2. These results together with the fact that no ellipticity changes occurred at $195 \mathrm{~nm}$ ((d) in Fig. 2) and the other wavelengths in mixing the same $2.0 \times 10^{-2}$ $\mathrm{mol} / \mathrm{liter} \mathrm{SDS}$ solution with $1.0 \times 10^{-5} \mathrm{~mol} / \mathrm{liter}$ bovine serum albumin solution, support the determination that the observed time course is not an artificial one which is occasionally observed in stopped-flow measurements. In addition, no ellipticity changes were observed at any wavelength adopted here in mixing the $\alpha$-chymotrypsin solution with the other electrolite solutions or solution of lower SDS concentrations, indicating that heat of mixing is negligible. Therefore, the observed process was concluded

* The CD spectra of the solution containing only $\alpha-$ chymotrypsin begin to change when leaving for $10 \mathrm{hr}$ at $25^{\circ} \mathrm{C}$. Especially, in the presence of $0.5 \sim 4.0 \times 10^{-3}$ $\mathrm{mol} /$ iiter SDS, the CD spectra of the protein change within 1 to $2 \mathrm{hr}$. 


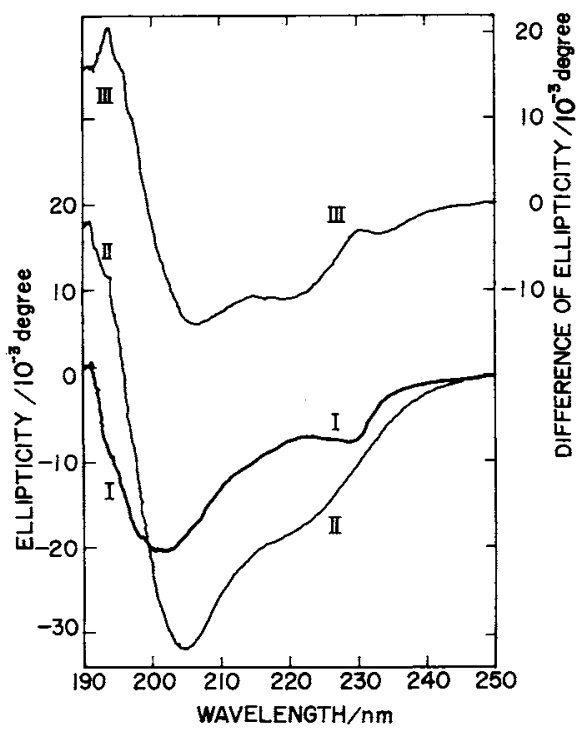

Fig. 1. The Typical Circular Dichroic Spectra of Solution of $\alpha$-Chymotrypsin in the Absence (I) and the Presence (II) of $2.0 \times 10^{-2} \mathrm{~mol} /$ liter SDS and the Difference Circular Dichroic Spectrum (III) of Them at $25^{\circ} \mathrm{C}$.

The concentration of the protein was $1.0 \times 10^{-5} \mathrm{~mol} / \mathrm{liter}$ and the thickness of the cell used was $1.0 \mathrm{~mm}$. The time constant and the scanning speed of the spectropolarimeter were set to be $1.0 \mathrm{sec}$ and $20 \mathrm{~nm} / \mathrm{min}$, respectively. These spectra are the averages of 8 repetitions.

to correspond the conformational change of $\alpha$-chymotrypsin induced by the addition of SDS. As seen in Fig. 3, a semilogarithmic plot of $\left|[\theta]_{t}-[\theta]_{t=\infty}\right|$ vs. time, $t$, gave a linear relationship between them over the time range in which ellipticity clearly changed. So, the conformational change of the protein may be treated as a first-order reaction. The forward rate constants of the conformational change, probably increase of helix content were calculated from the slopes in such plots and tabulated in Table I. The time courses at the three wavelengths approximately gave the same rate constant as easily anticipated from the plots in Fig. 3. The values of the rate constant are one order of magnitude greater than those obtained by thermal denaturation of the protein, ${ }^{7)}$ while
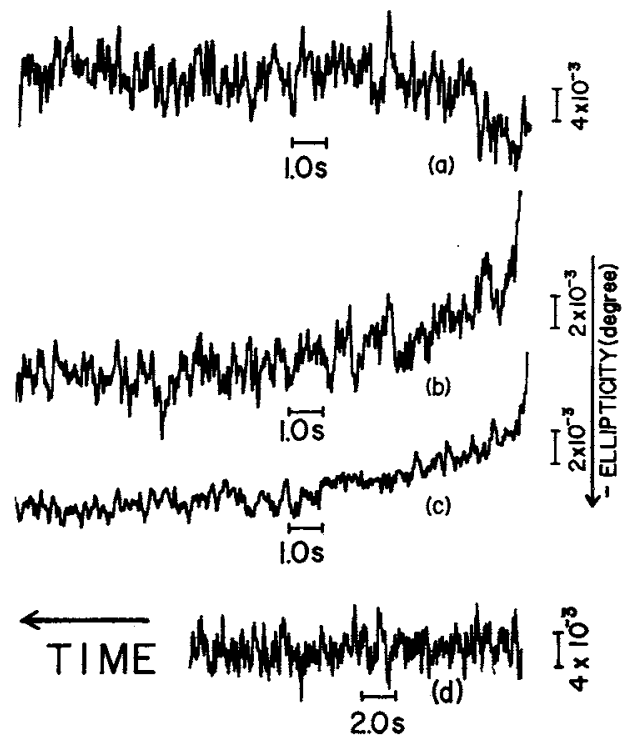

FIG. 2. The Typical Traces of Ellipticity Changes of 195 (a), 206 (b) and $222 \mathrm{~nm}$ (c) at $25^{\circ} \mathrm{C}$.

The final concentrations of SDS and $\alpha$-chymotrypsin were $2.0 \times 10^{-2}$ and $1.0 \times 10^{-5} \mathrm{~mol} / \mathrm{liter}$, respectively. The trace (d) presents the case of no ellipticity change observed at $195 \mathrm{~nm}$ in the same time range, in mixing SDS solution and bovine serum albumin solution. The final concentrations of SDS and the protein in this case were $2.0 \times 10^{-2}$ and $1.0 \times 10^{-5} \mathrm{~mol} / \mathrm{liter}$, respectively. The traces (a) and (d) are the averages of 32 repetitions and the traces (b) and (c) are the averages of 8 repetitions.

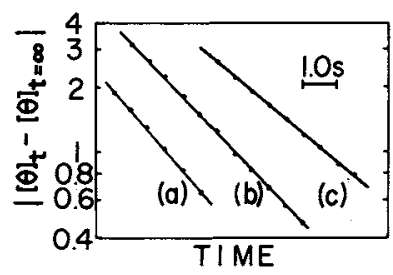

FIG. 3. Semilogarithmic First-Order Plots for the Approach to Equilibrium on the Three Time Courses (ac) in Fig. 2.

The quantities representing $\left|[\theta]_{t}-[\theta]_{t=\infty}\right|$ are taken as a unit in $4 \times 10^{-3}$ (a) and $2 \times 10^{-3}$ degree (b, c) on the basis of best fit curves drawn on time course in each case.

Table I. Forward Rate Constants, $k$ of Conformational Change of $\alpha$-Chymotrypsin at SeVeral SDS CONCENTRATIONS

\begin{tabular}{lcccccccc}
\hline $\mathrm{SDS} / 10^{-3} \mathrm{~mol} / \mathrm{liter}$ & 5.0 & 6.0 & 8.0 & 14 & 18 & 20 & 24 & 30 \\
\hline$k^{*} / 10^{-1} \mathrm{~s}^{-1}$ & 0.40 & 1.3 & 2.5 & 3.4 & 3.7 & 3.8 & 3.8 & 3.8 \\
\hline
\end{tabular}

* The values were obtained from the results at $206 \mathrm{~nm}$. The time courses at 195 and $222 \mathrm{~nm}$ gave the rate constant to be 4.1 and $3.5 \times 10^{-1} \mathrm{~s}^{-1}$ at $2.0 \times 10^{-2} \mathrm{~mol} /$ liter SDS. Experimental error at $206 \mathrm{~nm}$ is within $10 \%$. 
the helix content decreases in the thermal denaturation. In the CD stopped-flow measurements, the ellipticity changes are observed above $5.0 \times 10^{-3} \mathrm{~mol} / \mathrm{liter}$ SDS as stated above. However, this concentration of SDS is not directly correlated with the value of the CMC in the buffer, because the SDS molecules bind to protein as free monomers. ${ }^{8,9)}$ The dependence of the rate constant on the SDS concentration seems to reflect the extent of denaturation induced by binding of SDS.

It is concluded that the CD stopped-flow spectroscopy in far ultraviolet region can be effectively applied to conformational change of polypeptide containing no aromatic amino acids.

Acknowledgments. The authors express their heartfelt thanks to deceased Professor Masaji Miura for his encouragement and cooperation in the early stage of this work. They are also pleased to acknowledge the cooperation of Mr. Kikuo Shirawachi of Japan Spectroscopic Company with circular dichroic measurements.

\section{REFERENCES}

1) P. M. Bayley and M. Anson, Biopolymers, 13, 401 (1974); J. Phys., E-7, 481 (1974); Biochem. Biophys. Res. Commun., 62, 717 (1975).

2) K. Nitta, T. Segawa, K. Kuwajima and S. Sugai, Biopolymers, 16, 703 (1977).

3) I. Tabushi, K. Yamamura and Y. Nishiya, Tetrahedron Lett., 49, 4921 (1978).

4) J. Luchins and S. Beychok, Science, 199, 427 (1978).

5) Y. Sano and H. Inoue, Chem, Lett., 1087 (1979).

6) A. H. Hunt and B. Jirgensons, Biochemistry, 12, 4435 (1973).

7) F. M. Phol, Eur. J. Biochem., 4, 373 (1968).

8) J. Steinhardt and J. A. Reynolds, "Multiple Equilibria in Protein," Academic Press, New York, 1969 , pp. $239 \sim 302$.

9) T. Takagi, K. Shirahama, K. Tujii and K. Kubo, Tanpakushitsu Kakusan Koso, 21, 811 (1976) (in Japanese). 